\title{
Staphylococcal toxic-shock syndrome
}

INSERM

\section{Source}

INSERM. (1999). Orphanet: an online rare disease and orphan drug data base.

Staphylococcal toxic-shock syndrome. ORPHA:99919

Staphylococcal toxic shock syndrome (staphylococcal TSS) is an acute disease mediated by the production of superantigenic toxins, characterized by high fever, skin rash followed by skin peeling, hypotension, vomiting, diarrhea and potentially leading to multisystem organ failure and caused by a Staphylococcus aureus bacterial infection. 